\title{
Nomes de famílias de origens portuguesa e espanhola em lápides do cemitério de Iguatu- PR
}

\author{
Family names of Portuguese and Spanish origin on tombstones of the \\ Iguatu- PR cemetery
}

\author{
Fernando Hélio TAVARES de BARROS* \\ Grasiela Veloso dos SANTOS HEIDMANN** \\ Neusa Inês PHILIPPSEN ${ }^{* * *}$
}

\begin{abstract}
RESUMO: O Estado do Paraná, em particular sua região oeste, foi uma fronteira agrícola que atraiu (i)migrantes de diversas origens. Uma maneira de visualizar essa história de ocupação humana é através da paisagem linguística. Este trabalho tem como foco o estudo da Antroponímia de origem ibérica no município de Iguatu - PR por meio da paisagem linguística cemiterial. Para tanto, foram selecionadas 21 iconografias, constituídas por lápides de cemitério, nas quais foram identificados 27 nomes de família. Por meio da consulta de fontes lexicográficas (MACHADO, 1984, 1977; GUÉRIOS, 1973; NUNES; KREMER, 1999; TIBÓN, 1986, 2001; LEITE DE VASCONCELOS, 1928, 1931 etc.) foi possível expor as descrições etimológicas existentes de cada antropônimo estudado e os aspectos históricos de seu uso na história da língua. A maioria dos nomes analisados possui uma relação com a história e a
\end{abstract}

\begin{abstract}
The State of Paraná, in particular its western region, was an agricultural frontier that attracted migrants from various origins. One way to approach this history of human occupation is applying the linguistic landscape. This work focuses on the study of Iberian Anthroponymy in the municipality of Iguatu - PR through the linguistic landscape of cemetery. For this purpose, 21 iconographies were selected, consisting of cemetery gravestones, where 27 family names were identified. Consulting lexicographical bibliography (MACHADO, 1984, 1977; GUÉRIOS, 1973; NUNES; KREMER, 1999; TIBÓN, 1986, 2001; LEITE DE VASCONCELOS, 1928,1931 etc.) enabled us to describe the existing etymology of each anthroponym studied and the historical aspects of its use in the history of the language. Most of the names studied were associated to the history and physical or human nature of the Iberian Peninsula.
\end{abstract}

\footnotetext{
* Doutor em Linguística pela Universität Bremen, Alemanha. ORCID: https://orcid.org/0000-0002-98932775. tavaresd@uni-bremen.de

${ }^{* *}$ Doutora em Linguística pela UFMT, Campus Cuiabá. ORCID: https://orcid.org/0000-0002-1483-2946. grasinhavs@hotmail.com

*** Professora adjunta na UNEMAT, Campus Sinop. ORCID: https://orcid.org/0000-0003-0406-3984. $\underline{\text { neinph@yahoo.com.br }}$
} 
natureza física ou humana da Península

Ibérica.

PALAVRAS-CHAVE: Antroponímia ibérica. Paisagem linguística. Léxico. KEYWORDS: Iberian Anthroponymy. Nomes de família. Iguatu - Paraná.

\section{Introdução}

Apesar das lápides de cemitério se constituírem material pouco utilizado nas ciências da linguagem, esse tipo de paisagem linguística ${ }^{1}$ reserva uma rica fonte para o estudo do léxico e para a investigação onomástica. No nosso caso, no patrimônio onomástico das línguas portuguesa e espanhola. O cemitério é um espaço pleno de história. Além da paisagem linguística cemiterial revelar a origem e a ordem de chegada dos colonizadores de uma dada localidade, ela também mostra a hierarquia e o prestígio social que cada nome de família goza.

Esse estudo tem por objetivo analisar e descrever etimologicamente os nomes de famílias ${ }^{2}$ de raízes portuguesa e espanhola em lápides do Cemitério Municipal de Iguatu - PR, município localizado no vale do Piquiri³ ${ }^{3}$ De maneira geral, vamos tratar da Antroponímia ibérica.

O nosso propósito é por meio da coleta de antropônimos na paisagem linguística compor um corpus para a futura elaboração de um dicionário regional de

\footnotetext{
${ }^{1}$ As lápides constituem uma paisagem linguística, visto que os dados apresentados são fotografias de antropônimos expostos em espaço público e que nomeiam micro espaços de um cemitério. Conforme Landry e Bourhis (apud GORTER, 2006, p. 2), paisagem linguística é "the language of public road signs, advertising billboards, street names, place names, commercial shop signs, and public signs on government buildings combines to form the linguistic landscape of a given territory, region, or urban agglomeration". Gorter (2006, p. 2) ainda acrescenta que "they are concerned with the use of the language in its written form in the public sphere".

${ }^{2}$ Nesse artigo, paralelo ao termo nome de família, também são usados antropônimo, sobrenome ou cognome familiar.

${ }^{3}$ Esse estudo não tem como foco descrever os aspectos extralinguísticos que proporcionaram a transmissão dos nomes de famílias ibéricas no Brasil. Sabemos, por exemplo, que sobrenomes ibéricos foram atribuídos às famílias de origem africana, indígena, entre outras. Essa atribuição se deu por motivos históricos relacionados à submissão e ao apagamento dessas culturas. Trata-se de um caso de imposição antroponímica que alterou a identidade desses indivíduos.
} 
nomes de família, com o fim de registrar a Antroponímia local. Servindo essa como fonte de investigação para a Etnografia, a Onomástica e a Historiografia. Além disso, estudos dessa natureza auxiliam na investigação da Antroponímia ibérica na América portuguesa, particularmente, suas transformações e sua distribuição no espaço social e geográfico ${ }^{4}$.

Como base de consulta lexicográfica, utilizamos os dicionários onomásticos de Machado (1984; 1977), Guérios (1973), Nunes e Kremer (1999), Tibón (1986; 2001), Lopez-Mendizabal (1958), o DIT (Dicionário Infopédia de Toponímia), as obras de Leite de Vasconcelos $(1928 ; 1931)$ e de Tavora $(1989)^{5}$. Somam-se, ainda, aspectos quantitativos apresentados no sítio web sobre Cartografia dos apelidos de Galícia (doravante CAG), do Instituto da Língua Galega da Universidade de Santiago de Compostela ${ }^{6}$, coordenado por Ana Isabel Boullón Agrelo e Xulio Sousa Fernández . Esse trabalho também se constitui um registro etnográfico dos descendentes de imigrantes portugueses e espanhóis nessa região, uma vez que pode mostrar a territorialidade desses grupos, além de aspectos sociais e históricos do lugar.

Estruturamos o texto na seguinte ordem: uma breve descrição dos estudos de nomes de família e sua importância, após, apresentamos alguns aspectos históricos e geográficos de Iguatu - PR, em seguida dispomos o corpus de paisagem linguística recolhido no cemitério dessa localidade acompanhada das descrições etimológicas, comentários analíticos e as considerações finais.

\footnotetext{
${ }^{4}$ Considerando que o estudo da Antroponímia contribui para entender os movimentos populacionais, em outras palavras, povoamento e despovoamento de uma certa região (BAYLON; FABRE, 1982, p. 1112).

${ }^{5}$ A obra de Tavora (1989) oferece informações de genealogia portuguesa. Apesar da riqueza que a genealogia pode oferecer ao estudo da Antroponomástica, cabe ao estudioso de nomes ter bastante cuidado, rigor e desconfiança com o trato desse tipo de fonte. Isso pelo fato da Genealogia ser um campo, por vezes, nebuloso e traiçoeiro. Todavia, não se pode ignorar o patrimônio que ela fornece à Onomástica.

${ }^{6}$ Disponível em: https://ilg.usc.es/cag/. Acesso em: 25 mar. 2020.

${ }^{7}$ Os dados de frequência e distribuição dos nomes são baseados no censo demográfico de 2001.
} 


\section{$2 \mathrm{O}$ estudo de nomes de famílias}

O nome de família, conhecido também como sobrenome ou apelido, "é designação de família, transmitida ordinariamente de geração em geração" (LEITE DE VASCONCELOS, 1928, p.11). Os nomes de família fazem parte dos interesses da Antroponomástica ou Antroponímia - do grego anthropos 'homem' e onoma 'nome' (BAYLON; FABRE, 1982). Essa, somada ao campo vizinho, a Toponomástica ou Toponímia - do grego topos 'lugar' e onoma 'nome' (BAYLON; FABRE, 1982), compõem a Onomástica - ciência filiada à Lexicologia, que se dedica ao estudo dos nomes próprios. Como elucida Dauzat (1951), a Antroponímia tem como abordagem metodológica investigar a origem dos nomes de pessoas e a sua evolução, bem como a etimologia das palavras.

Para Tibón (1986), o estudo dos nomes de pessoa é atraente pelo seu aspecto deleitoso e rico em surpresas. Sua imponência se dá pelos seus alcances filológicos, históricos e sociológicos ${ }^{8}$. Nesse sentido, Dauzat (1951) salienta que é próprio do interesse das pessoas quererem saber a procedência de seus nomes ${ }^{9}$. Nem todos os nomes de família, continua o autor, são de significação transparente. Grande parte representa um enigma para a maioria das pessoas ${ }^{10}$. O estudo dos nomes de família não desperta interesse apenas da Lexicologia e da Lexicografia na composição de dicionários, mas, atualmente, também da Geografia dos nomes de família ${ }^{11}$. Essa que

\footnotetext{
8 „Los nombres de persona compendian la historia de la civilización. Su estudio no es sólo deleitoso y rico en sorpresas, sino que se impone por sus alcances filológicos, históricos y sociológicos" (TIBÓN, 1986, p. 7).

9 "Chacun s'intéresse à son nom - à ses noms - et voudrait en connaître le sens originaire" (DAUZAT, 1951, p. 6).

10 "Si quelques noms de famille ont une signification transparente (...), la plupart sont énigmatiques pour le grand public" (DAUZAT, 1951, p. 6).

${ }^{11}$ Campo disciplinar que além de estudar os nomes de família possui como objetivo transpô-los para uma base cartográfica. Assim como elucida Goossens (1996): "Familiennamengeographie (FNG) ist die Untersuchung von FN und FN-Typen in ihrer räumlichen Verbreitung auf der Grundlage kartographischer Darstellungen" (GOOSSENS, 1996, p. 1141).
} 
por meio da produção de mapas mostra a manutenção e a difusão dos antropônimos no espaço geográfico.

Diversos meios de coleta de antropônimos são válidos nos estudos onomásticos. Listas de telefones, jornais, placas de rua, registros paroquiais, cartas privadas, listas eleitorais, entre outros. Em nosso estudo, por sua vez, nos concentramos em coletar e analisar lápides de cemitério.

\section{As imigrações portuguesa e espanhola no Brasil}

O elemento luso no Brasil se remete à imigração portuguesa que já se inicia no Brasil desde os primórdios do Império Português (1500-1822). As diversas ondas migratórias ocasionadas pela política colonizadora da Coroa Portuguesa foram em direção a diferentes zonas geográficas da América portuguesa, tanto às regiões da corrida do ouro (Minas Gerais, Goiás, Bahia e Mato Grosso) quanto às áreas litorâneas de cultura pesqueira e interioranas de grandes latifúndios impulsionadas pela concessão de sesmarias aos imigrantes. A imigração após a Independência do Brasil (1822) foi mais centrada às áreas urbanas - em particular, a Grande São Paulo e Rio de Janeiro - ou do cultivo do café, no qual o imigrante português se torna mão de obra em substituição à escravidão negra após a abolição ${ }^{12}$.

A imigração espanhola, por sua vez, é menor que a portuguesa e mais centrada em alguns pontos geográficos do Brasil, em destaque no Estado de São Paulo. O clímax dessa corrente migratória se dá, principalmente, nas décadas finais do século XIX. No contexto paulista, o imigrante espanhol é, entre outras ocupações, mão de obra na cafeicultura $^{13}$. Cabe aí salientarmos que o Estado de São Paulo foi e é um grande

\footnotetext{
12 Para se entender melhor a história da imigração portuguesa no Brasil, cabe citarmos as obras de Matos et al. (2008) e Arruda (2013).

${ }^{13}$ Como trabalhos que tratam da imigração espanhola no Brasil, cabe evidenciarmos os trabalhos de Blanco (2009) e Canóvas (2001).
} 
radiador de migrações, em particular, em direção ao Estado do Paraná, no qual se situa o município de Iguatu ${ }^{14}$.

\section{Aspectos históricos de Iguatu - PR}

Iguatu tem em seu nome prováveis raízes no tupinismo ikatu - água boa, salubre, doce - na acepção de Boudin (1978, p. 73), já na proposta etimológica de Tibiriçá (1985, p. 58), o nome teria origem de yguáytu - cachoeira dos musgos. O município está localizado no oeste do Paraná e pertence ao polo regional de CascavelPR. Iguatu tem uma população estimada em 2.304 pessoas, conforme os dados do IBGE (Instituto Brasileiro de Geografia e Estatística) ${ }^{15}$. O processo de colonização do município, como fronteira agrícola, inicia no ano de 1958.

Inicialmente conhecida por Gleba n.9, e por pouco tempo Jaborandi, Iguatu recebeu as primeiras famílias de colonos no início dos anos de 1960. A emancipação de Iguatu se deu em 1990. Entre as comunidades que compõem o município estão Olaria Velha, Morro do Tatu, Vai ou Racha, Centenário, Água da Onça, Estradas Longuinópolis, Braganey, BR 369 e Samália. O município recebeu colonos de origens paulista, mineira, nordestina, gaúcha e catarinense. Entre os povoadores sabe-se que uma parcela veio de zonas do Brasil de colonização portuguesa e de regiões onde se assentaram imigrantes espanhóis e portugueses ${ }^{16}$. A agropecuária e a monocultura do milho, do fumo e da soja são os principais cultivos do município.

\section{Corpus recolhido e sua descrição}

O material apresentado nesse estudo compõe-se de lápides do cemitério municipal de Iguatu -PR. O corpus foi recolhido no mês de abril de 2017. Nele foram

\footnotetext{
${ }^{14}$ Cf. Cardoso e Westphalen (1986).

15 Censo de 2010. Fonte: https://cidades.ibge.gov.br/brasil/pr/iguatu/panorama. Acesso em: 25 mar. 2020.

${ }^{16}$ Não se sabe de relatos de imigração direta da Península Ibérica para o município de Iguatu - PR.
} 
encontrados nomes de famílias de origens alemã, italiana, eslava, portuguesa e espanhola. Nesse estudo, resolvemos tratar apenas dos antropônimos ibéricos ${ }^{17}$. Dispusemos as iconografias em forma de tabela, sendo que cada uma contém duas células e, por vezes, apenas uma. Em cada célula há uma iconografia. Abaixo de cada tabela estão os referidos antropônimos. Nas iconografias há, frequentemente, mais de um nome de família. Eles, geralmente, iniciam com letras diferentes, o que dificulta a sua organização alfabética em forma de lista. Por essa razão, os nomes estão expostos de maneira aleatória.

Nosso interesse recai na descrição dos nomes de famílias, portanto, os prenomes não estão contemplados nas descrições etimológicas. Além de dados específicos do léxico, procuramos conjugar informações históricas do uso da forma antroponímica.

A seguir apresentamos as descrições etimológicas de todos os nomes de famílias identificados como de raiz ibérica ${ }^{18}$.

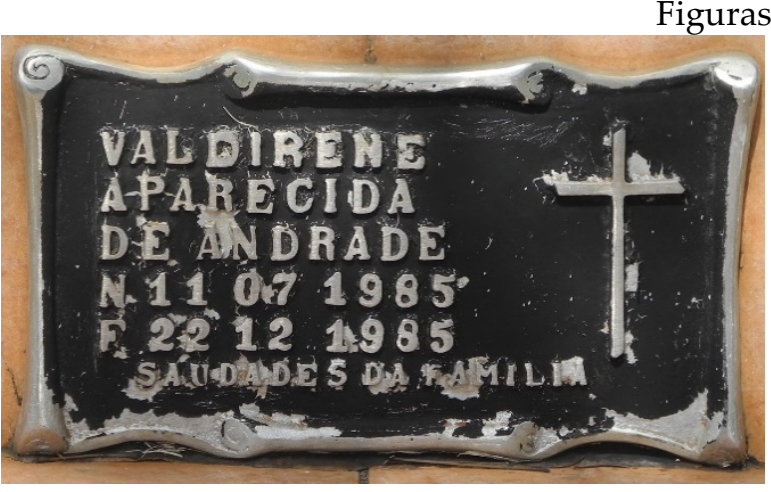

Valdirene Aparecida de Andrade

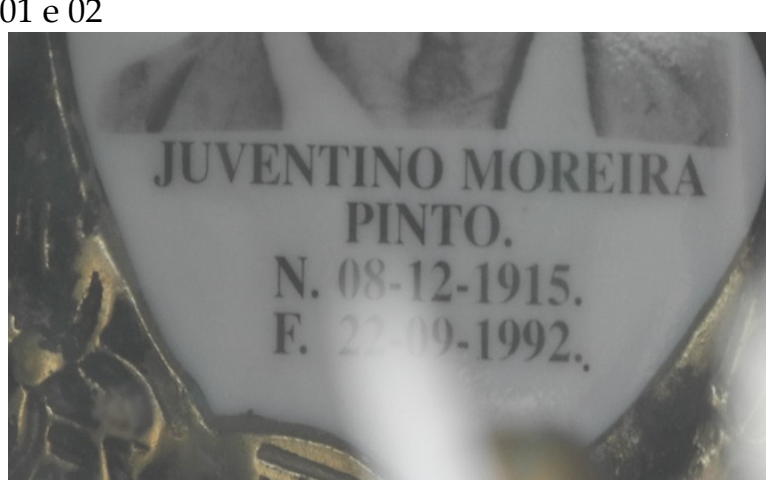

Juventino Moreira Pinto

Fonte: Corpus recolhido pelos autores.

${ }^{17}$ As lápides apresentadas nesse trabalho representam todos os casos de antropônimos ibéricos encontrados no cemitério municipal de Iguatu - PR.

${ }^{18}$ É importante salientarmos ao leitor que nós não temos dados históricos sobre a origem genealógica dos indivíduos nominados nas lápides que fotografamos para o nosso corpus. Por essa razão, não se pode afirmar que a origem portuguesa ou espanhola do antropônimo revela a procedência dos seus antepassados. O que podemos afirmar é que os nomes de família aqui tratados estão registrados na literatura lexicográfica como pertencentes ao patrimônio antroponímico ibérico. 
De Andrade. É, talvez, variante de andr- do grego andrós - macho, varão, homem (MACHADO, 1977, p. 249). Andrade é sobrenome antigo, de origem geográfica provavelmente com raízes na Galiza (MACHADO, 1984, p. 133), o que a própria prep. de revela. Para Tavora (1989, p. 80), o antropônimo deriva da vila de Andrada na Galiza e dos membros dessa vila, que passaram para Portugal, apenas os de Rui Freire de Andrade, no século XIV, deixaram descendência nesse país. Há uma obscuridade em relação a uma origem mais antiga, pois Machado (1984) ressalta haver registros no século XI com grafia Andreati e Andriati (nomes geográficos). No entanto, ainda em 946, já aparecia o registro Antriati (villa), gen. de um antropônimo Antriatus, ainda obscuro. Na Cartografia dos Apelidos de Galícia, esse antropônimo ocorre com bastante frequência, 3.913 registros, com maior concentração no Conselho de Carballo, Província de Corunha (0.5282\%). Nunes e Kremer (1999) documentaram de Andrade na Antroponímia da Madeira ${ }^{19}$.

Moreira. De amoreira > amora - do grego mŏron, fruto da amoreira, pelo lat. mōru(MACHADO, 1977, p. 235). De motivação toponímica, segundo Machado (1984, p. 1022) e Guérios (1973, p. 160), é frequente em Portugal ${ }^{20}$ e na Galiza e parece ter relação com a importância da criação de bicho da seda nesses lugares, pois a amoreira "árvore da amora" é subsídio para essa produção. Já Tavora (1989, p. 259), refere o sobrenome de família como originário da Freguesia de Santa Maria de Moreira, na comarca de Celorico de Basto, na qual o cavaleiro Pedro Pires Moreira, contemporâneo dos Reis D. Sancho I e D. Afonso II, o carregava. O uso com a preposição de (Moreira), segundo Machado (1984), já se perdeu, junto com a noção de origem toponímica, a não ser que se faça relação com o nome da árvore que o originou. Este antropônimo, nos dados da

\footnotetext{
19 "Andrade (Pero Gonçalves d) Calheta a. 1534" (NUNES; KREMER, 1999, p.263).

${ }^{20} \mathrm{Na}$ Madeira, Nunes e Kremer (1999) documentaram os primeiros registros do antropônimo Moreira já a partir de 1481-1482. Entre os registros, uma "Moreira (Catarina) vendedeira de peyxe Funchal [a.1495-1496]" (NUNES; KREMER, 1999, p.600).
} 
CAG, apresenta 5.959 ocorrências, com maior concentração no Conselho de Vigo, Província de Pontevedra $(0.1416 \%)$.

Pinto. Pinto > pito > lat. pìttu "formado de uma raíz pitt-, provavelmente pré-latina" (MACHADO, 1977, p. 378). Antropônimo derivado de alcunha, para Leite de Vasconcelos (1928), a explicação é justificada pela relação com ave, a cria da galinha, mas também pela cor (rosto, cabelos e olhos). Segundo o autor, o nobre português D. João Garcia de Sousa "foi chamado Pinto por suas muitas perfeyçõens naturays e gentileza" (p. 231). Conforme Tavora (1989), o nome fixou-se ao tomar descendência com outros nomes e linhagens, como "de Gundar", "de Sousa", "da Maia", "de Baião" e outros. Machado (1984, p. 1179) destaca que como topônimo é frequente na Galiza, na Província de Orense. Confirma-se a presença nos dados da CAG, com total de 777 ocorrências, em maior quantidade na Província de Pontevedra, Conselho de Vigo (0.0194\%). A forma também é registrada na Antroponímia italiana (CAFFARELLI; MARCATO, 2008, p. 1345) ${ }^{21}$.

Fig. 03 e 04

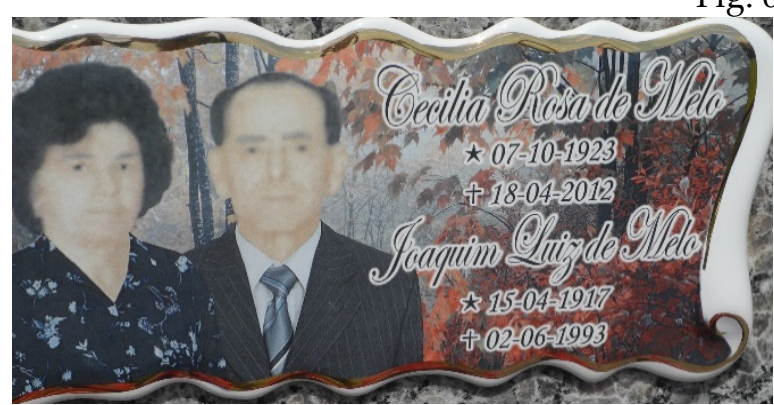

Cecilia Rosa de Melo Joaquim Luiz de Melo

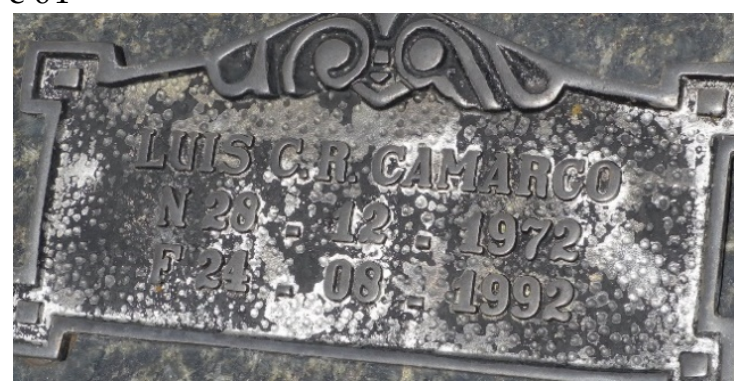

Luis C. R. Camargo

Fonte: corpus recolhido pelos autores.

21 "Più numeroso 16 volte, Pinto è il 205 cognome per frequenza in Italia, il 30 in Puglia, il 69 in Basilicata e l'89 in Campania; si tratta dunque di forma tipicamente meridionale" (CAFFARELLI; MARCATO, 2008, p. 1345). 
De Melo. Do lat. merŭlu-, melro > merlo> Mello, Melo (MACHADO, 1984, p. 976). Leite de Vasconcelos (1928, p. 166) o coloca na lista de nomes de origem geográfica, assim como também o citam Guérios (1973, p. 155) e Machado (1984, p. 976), para as formas Merloo e Merlo em Portugal antigo. Machado (1984) o classifica como originária do gr. Mèlo, "ilha das Cíclades (hoje Milo), pelo lat. Mèlos ou Mèlus" (MACHADO, 1984, p. 976). No entanto, também Guérios (1973, idem) afirma o nome ter origem por alcunha, advinda de melro (ave), "do latim mérulus: melro, merlo [...]", na forma Mello teria ocorrido assimilação de -r ao -l.

Para Tavora (1989, p. 248-249), o nome deriva de uma alcunha e teria provindo de D. Soeiro Reimondes (o Merlo ou Melro), que, após fundação da Vila de Melro na Beira e casamento, daria início à forma fixa Melo. Conforme Machado (1984), Melo é topônimo português em Alcácer do Sal, Alpiarça, Campo Maior, Gouveia, Lisboa, Montemor-o-Novo Porto e Torres Novas (MACHADO, 1984, p. 976). Na estatística da CAG, o nome apresenta registro de 161 ocorrências, com maior predominância no Conselho de Tomiño, Província de Pontevedra (0.2186\%). No entanto, também se registra a forma Demelo (sem fronteira de preposição), com 9 ocorrências $(0.0015 \%)$, na Província de Pontevedra. A forma Merlo é registrada, mas em pequena quantidade, apenas 7, assim como Mello com consoante dupla. Na Antroponímia italiana, Caffarelli e Marcato (2008) registram a forma Mèllo22.

Camargo. Sobrenome de origem geográfica e espanhol. Segundo Tibón (2001, p. 54), teria surgido na Província de Santander. Para Machado (1984, p. 322), além de ser originário de Santander, também o é de Granada e teria sua presença no Brasil (Rio Grande do Sul, São Paulo, Amazonas, Minas Gerais e Paraná), mas também usado em

\footnotetext{
22 "Dal topônimo lombardo Mello, comune della provincia di Sondrio, o da una forma accorciata di (Giaco)mello; in area meridionale sarà da accostare alle basi di Méle se non anche a melo o al greco mélos 'canto'; un nome Melo, Melus è attestato in carte medievali pugliesi" (CAFFARELLI; MARCATO, 2008, p. 1108).
} 
Lisboa (LEITE DE VASCONCELOS, 1928, p. 298). Para Guérios (1973, p. 75), os Camargos de São Paulo descenderiam de José Ortiz de Camargo (de Castela Velha), que, por sua vez, provém do navegante espanhol D. Afonso Camargo. Na cartografia da CAG, se registram apenas 22 ocorrências, com distribuição linear nas Províncias de Ourense, Corunha e Pontevedra, 8, 8 e 6 ocorrências, respectivamente.

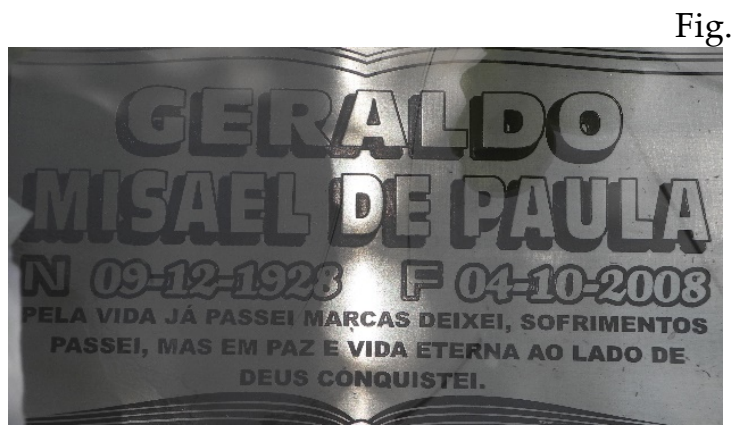

Geraldo Misael de Paula

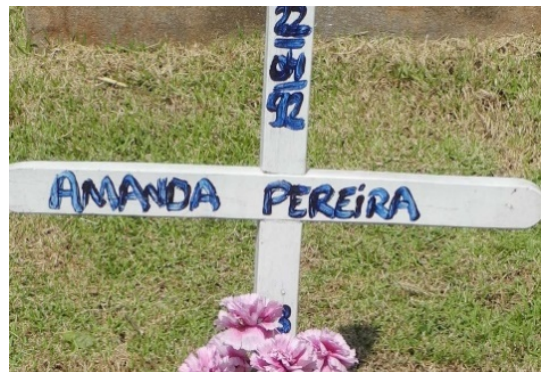

Amanda Pereira

Fonte: corpus recolhido pelos autores.

De Paula. Este sobrenome tem relação com santos cristãos, "os romanos usavam-no muito como sobrenome" (GUÉRIOS, 1973, p. 175). Assim, a origem é latina Paulus = Paullus e, por ser nome de santo, tinha por consequência reputar bom agouro aos que o adotavam (LEITE DE VASCONCELOS, 1928, p. 26). Conforme Machado (1984, p. 1142), é antropônimo feminino de Paul(l)us - Paulo e também existiu uma santa romana com este nome (347-404), outrossim, figura como nome que fora aplicado junto ao nome Francisco, em menção a São Francisco de Paula, nascido em Paola - Calábria. Ainda, segundo o autor, em Portugal é topônimo em Alcácer do Sal, Alenquer, Lisboa, Trancoso, Vieira do Minho, Vila Franca de Xira (1143). Nos dados da CAG, esse antropônimo não apresenta muitas ocorrências, apenas 57 registros, com predominância no Conselho e Província de Ourense (0.0193\%).

Pereira. Antropônimo português de origem geográfica, que está relacionado com o "lugar onde há peras ou pereiras" e teria relação com à casa de Bragança em Portugal 
(GUÉRIOS, 1973, p. 177). Frequente em Portugal23, Galícia e no Brasil: em São Paulo (MACHADO, 1984, p. 1161). Em registros mais antigos, pode ser encontrada a forma Pireira, em 1387 e 1418, conforme Machado (1984, p. 1161). Este nome é bastante disseminado em todo território da Galícia, apresenta registro na CAG com 24.081 ocorrências, presente em 237 Conselhos, com número maior na Província de Pontevedra, Conselho de Vigo, com 3.537 registros (0.6073\%).

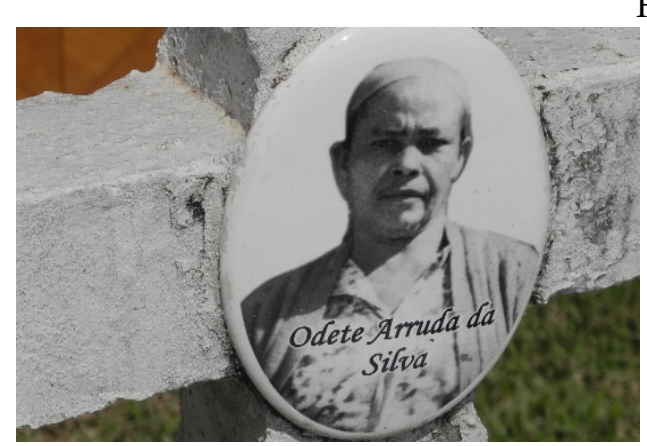

Odete Arruda da Silva
Fig. 07 e 08

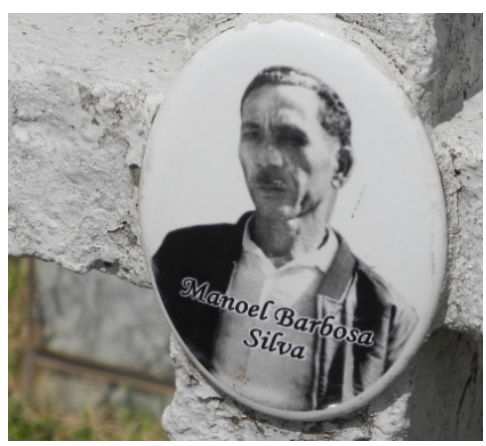

Manoel Barbosa

Fonte: corpus recolhido pelos autores.

Arruda. Do lat. rūta, com mesmo sentido, "notar ainda que os Árabes conheceram o voc. e escreveram-no com o art.: ar-rūta" (MACHADO, 1977, p. 322). Para Guérios (1973, p. 58), esse sobrenome português tem raízes toponímicas, “lugar onde há arruda (planta)", assim também o classifica Leite de Vasconcelos (1928, p. 165). O topônimo Arruda tem seu primeiro registro em 1172, e como nome de família já no séc. XVI (MACHADO, 1984, p. 171). Este antropônimo não apresenta registro no CAD.

Da Silva. Nome de origem toponímica, de etimologia latina, que significa "selva, floresta" e "nome de várias plantas" (GUÉRIOS, 1973, p. 199). Segundo Machado (1984, p. 1347), é muito frequente, mas relata que há casos em que parece ter relação

\footnotetext{
23 Nunes e Kremer (1999, p. 635) documentaram 14 variantes de Pereira (Pereyra, Perejra) na Antroponímia primitiva da Madeira.
} 
com a invocação de Nossa Senhora da Silva, Santa Beatriz da Silva (sec. XV) de família nobre e antiga. Tavora (1989, p. 324) afirma que o nome tem raízes remotas e nobres, pois é anterior à fundação da nacionalidade portuguesa e teria relação com a Casa Real de Leão. Na cartografia da CAG, aparece como um antropônimo numeroso, com 13.953 registros, presente em muitos Conselhos da Galícia, com ocorrências maiores em Vigo - 1532 (0.263\%), na Província de Pontevedra.

Barbosa. Derivado de barba > lat. barba (MACHADO, 1977, p. 389). Segundo Guérios (1973, p. 64), o nome tem raízes toponímicas e significa "lugar onde há muitas barbas de bode ou barbas de velho (plantas)". Os Barbosas descenderiam, segundo o autor, de D. Sancho Nunes de Barbosa. Em Leite de Vasconcelos (1928, p. 159), encontra-se mencionada uma grafia mais antiga, Barvosa, registrada como topônimo no ano de 1268. Machado (1984, p. 216) salienta que é muito frequente o topônimo com a forma Barbosa proveniente de nome, tais como, Casal da Barbosa, Monte do Barbosa, Quinta do Barbosa ou simplesmente relacionado à terra: abundância de plantas chamadas de barba: barbas de bode, barbas de velho etc., conforme já mencionado em Guérios (1973, idem). A CAG apresenta 1.911 ocorrências, com predominância no Conselho de Vigo (0.0754\%), Província de Pontevedra. Na Antroponímia primitiva da Madeira, Nunes e Kremer (1999) documentaram 4 ocorrências de Barbosa.

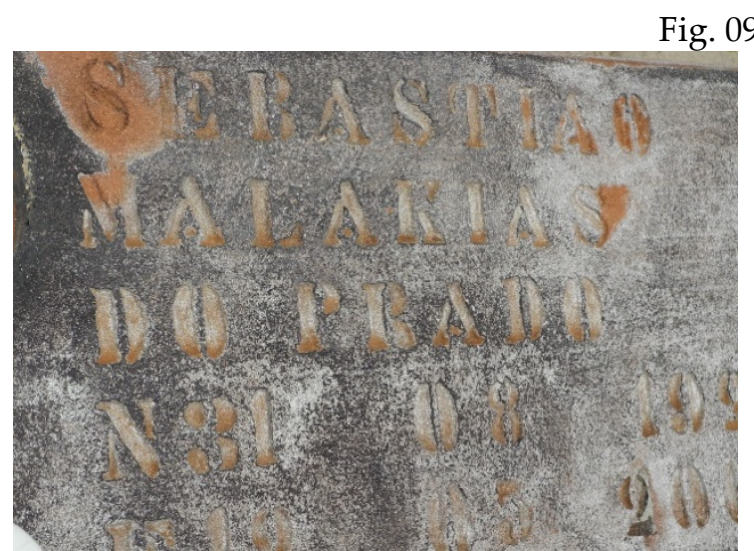

Sebastião Malakias do Prado

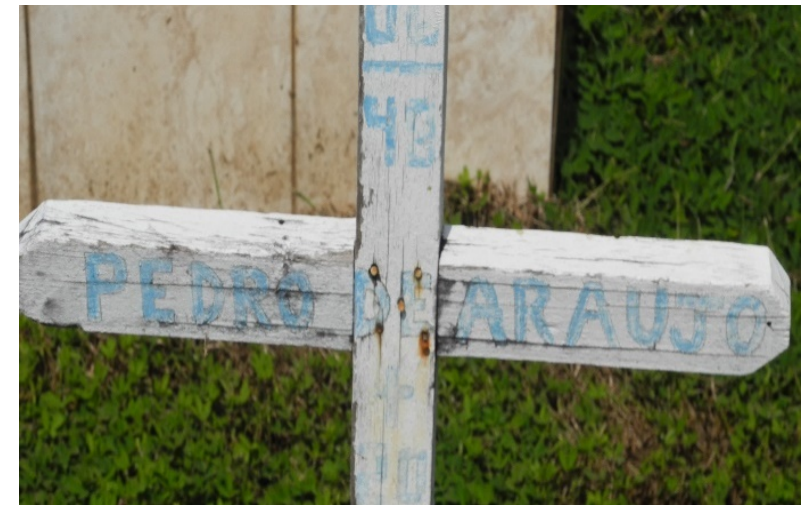

Pedro de Araujo

Fonte: corpus recolhido pelos autores. 
Do Prado. Segundo Machado (1977, p. 413), do lat. prātu- (prado, pradaria). Para Leite de Vasconcelos (1928, p. 166) e Guérios (1973, p. 181), esse sobrenome tem raiz toponímica. Guérios (1973, p. 181) relaciona a forma Prado com campina e com as formas no francês Dupré, Delprat (do prado). Para Tavora (1989, p. 293), o antropônimo parece ter sido fundado por D. Frei João Nunes do Prado (neto de D. Afonso III de Portugal), que teve filho com mesmo nome, do qual descende esse sobrenome. O nome tem ampla distribuição por vários Conselhos e Províncias nos dados da CAG, com total de 9099 ocorrências, destas, 1561 se concentram em Pontevedra, no Conselho de Vigo (0.268\%). Essa forma também está documentada na Antroponímia primitiva da Madeira ${ }^{24}$.

De Araujo. Consta na lista de nomes modernos tirados de nomes toponímicos e mencionados por Leite de Vasconcelos (1928, p. 166). Para Guérios (1973, p. 57), o nome teria advindo da Galiza, do castelo de Araúja, próximo ao rio Minho. Segundo o autor, o sobrenome teria chegado em Portugal por Pedro Pais de Araúja, a forma masculina passou a ser usada posteriormente, por se referir com frequência a homem. Já para Machado (1984, p. 153), a forma toponímica no feminino Araúja (Braga, Elvas) e masculino Araújos (Marco de Canaveses) tem origem obscura.

Tibón (2001, p. 20) registra Araujo como de origem vasca, "variante de Arauco (ara, arau 'helecho' (pt. bot. samambaia) y suf. loc. -co, com art. -a. Araucoa. dimin. Araucho, "pequeno helechal". Esse antropônimo também se apresenta na CAG, com 6353 ocorrências e maior concentração em Vigo, 1529 (02625\%), Província de Pontevedra. Araujo também se faz presente na Antroponímia primitiva da Madeira. ${ }^{25}$

\footnotetext{
24 "Prado (Joham de) Funchal a. 1466" (NUNES; KREMER, 1999, p. 641).

${ }^{25}$ Nunes e Kremer (1999) documentaram 15 ocorrências de Araujo.
} 
Fig. 11 e 12

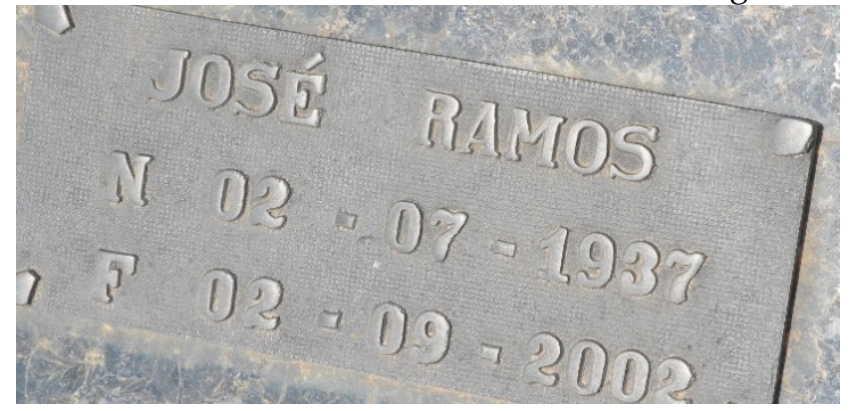

José Ramos

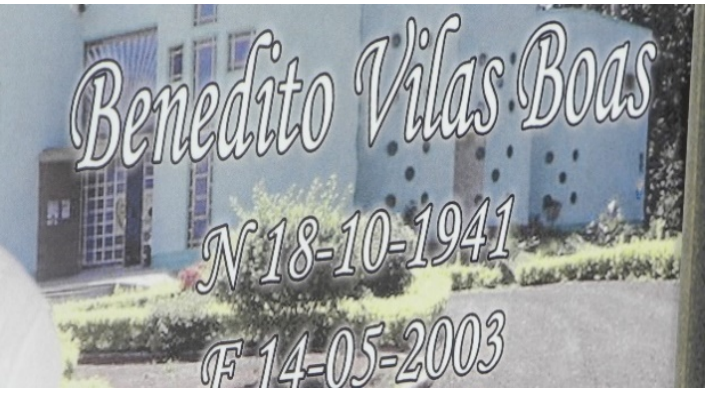

Benedito Vilas Boas

Fonte: corpus recolhido pelos autores.

Ramos. Do lat. rāmu-, "pernada (de árvore), ramo; fig., galhos de veado; ramificação (de cadeia de montanhas); ramificação de qualquer coisa" (MACHADO, 1977, p. 37). De raízes religiosas, segundo Machado (1984, p. 1238), esse nome de família era dado aos que nasciam no Domingo de Ramos, ou seja, o sexto domingo da Quaresma, "assim chamado da Procissão dos Ramos que se faz nesse dia, a comemorar a entrada triunfal de Cristo em Jerusalém, com palmas e ramos de oliveira" (MACHADO, 1984, p. 1238). O mesmo diz Tibón (2001, p.203), nome de caráter místico, "que se daba a los niños nacidos el Domingo de Ramos". O nome Ramos na CAG é de ampla distribuição e uso em todo o território galego. São registradas 16276 ocorrências, com maior concentração na Província e Conselho de Corunha - 2014 registros (0.4149\%).

Vilas Boas. Esse sobrenome tem motivação toponímica, ou seja, nome dado aos que nasceram em Vilas Boas. Esse topônimo nomeia lugares nas seguintes localidades portuguesas: Barcelos, Chaves, Coimbra, Ferreira do Alentejo e Vila Flor (MACHADO, 1984, p. 1478). Conforme Tavora (1989, p. 353), a primeira pessoa a receber esse antropônimo foi João Anes de Vilas Boas, senhor da Torre de Airó, do tempo do reinado de D. Afonso III. Nos dados da CAG, o antropônimo é registrado com pouca ocorrência, apenas 14, igualmente divididos nos Conselhos de Moaña e Vigo. No entanto, também se registra a forma Vilaboa, com maior ocorrência que a forma 
anterior (921) e mais concentração em Vigo (0.0513\%). Vilas Boas é forma documentada também na Antroponímia primitiva da Madeira. ${ }^{26}$

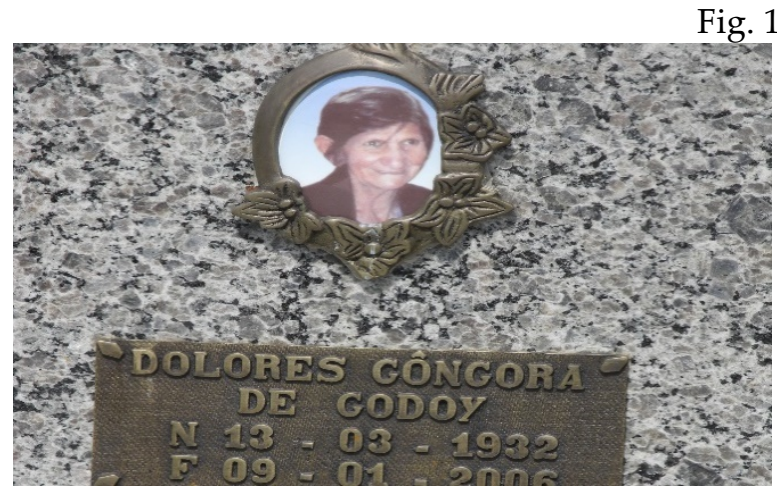

Dolores Gôngora de Godoy
Fig. 13 e 14

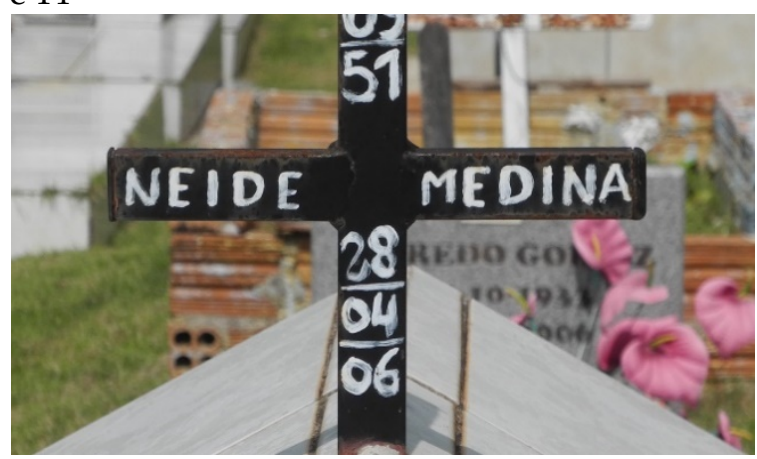

Neide Medina

Fonte: Corpus recolhido pelos autores.

Gôngora. Parece ser antropônimo com raízes na Espanha, em específico de origem vasca. Tibón (2001, p.108) registra o nome Góngora, como nome de família originado do gentílico da população residente no vale de Aranguren. Góngora vem de gamonal27, "<ango, 'gamón' y suf. -ra, com G protética". A mesma explicação etimológica nos dá Lopez-Mendizabal (1958, p.492). Gongora é topônimo na região de Navarra (País Vasco), conforme Lopez-Mendizabal (1958, p. 492). Como no espanhol, esse nome leva o acento agudo, o emprego do circunflexo nessa lápide mostra, possivelmente, um caso de lusitanização do sobrenome, talvez já em terras brasileiras. Considerando-se que não há o emprego do circunflexo na ortografia espanhola padrão. Esse antropônimo não apresenta ocorrência na CAG.

De Godoy. Segundo Guérios (1973, p. 117) e Machado (1984, p. 722), esse antropônimo é de origem espanhola. Sua variante portuguesa é Godói. Para Guérios (1973, p. 117), Godoy venha "talvez do lat. gothoni ou gothone" (itálico nosso). Machado (1984, p. 722)

\footnotetext{
26 “Vilas Boas (Jacome de) Funchal a. 1548” (NUNES; KREMER, 1999, p. 703).

${ }_{27}$ De gamón, cujo qual é denominação de uma planta da família das liliáceas de folhas largas e flores brancas. Fonte: DLE - RAE, disponível em: http://dle.rae.es/?id=IpVeY4k. Acesso em: 25 mar. 2020.
} 
diz que o nome é de "origem toponímica (Pontevedra), este do germânico gut-, <<deus >> + wîhs, <<santo >>". Apresenta 405 ocorrências na CAG, maior concentração em Vigo - 61 (0.0105\%), Província de Pontevedra.

Medina. Para Machado (1984, p. 969), trata-se de uma forma reduzida de Almedina (este um nome de lugar). O mesmo autor (idem, p. 969) registra a forma De Medina como vinda do espanhol e de origem toponímica espanhola (Badajoz, Burgos, Córdova, Oviedo, Sória, Valhadolide). Em 1440, já havia o registro de uma pessoa chamada "affonso de medjna scudeiro de vasco annes corte rreal" (idem, p. 969) e nos meados do séc. XIV um tal "Pero Fernamdez de Medina" de procedência castelhana.

Tibón (2001, p. 153) afirma que Medina é variação advinda da forma Madina (do árabe), o mesmo diz Guérios (1973, p. 155). Relacionado à forma Madina está o fato da cidade da Arábia Yathreb outrora ser chamada de Medinet-el-Nebi "a cidade do profeta" ou Medinet-Rasul-Allah “a cidade do apóstolo de Deus”. Maomé (esp. Mahoma) chegou a essa cidade depois de longa viagem pelo deserto (622) e residiu aí até sua morte (TIBÓN, 2001, p. 153). Menos de um século depois da fuga de Maomé (a hégira), foi fundada na Espanha a nova Medina (Medina Sidonia), e desde então surgem outras localidades com esse nome, motivadas pela sede terrena do profeta: Medina del Campo, de las Torres, del Pomar, entre outras (idem, p. 153). O nome tem registro nos dados da CAG, com 502 ocorrências e maior concentração em Vigo 149 (0.0256\%). A forma Medina também está documentada na Antroponímia primitiva da Madeira $^{28}$ e na Antroponímia italiana ${ }^{29}$.

\footnotetext{
${ }^{28}$ Entre as 4 ocorrências de Medina, um tal de Diogo de Medina "confeyteiro, Funchal [a.1504-1505]" (NUNES; KREMER, 1999, p. 587).

${ }^{29}$ Caffarelli e Marcato (2008) afirmam que a ocorrência de Medina na Itália setentrional se pode supor o mesmo que seja um derivado do topônimo Meda, mas também da cidade onde morreu Maomé ou da cidade espanhola de nome Medina. "Medina tratto dal toponimo Medina, città dove visse e morì Moametto, ma anche di varie città della Spagna da cui il cognome spagnolo e catalano Medina" (CAFFARELLI; MARCATO, 2008, p. 1104).
} 
Fig. 15 e 16

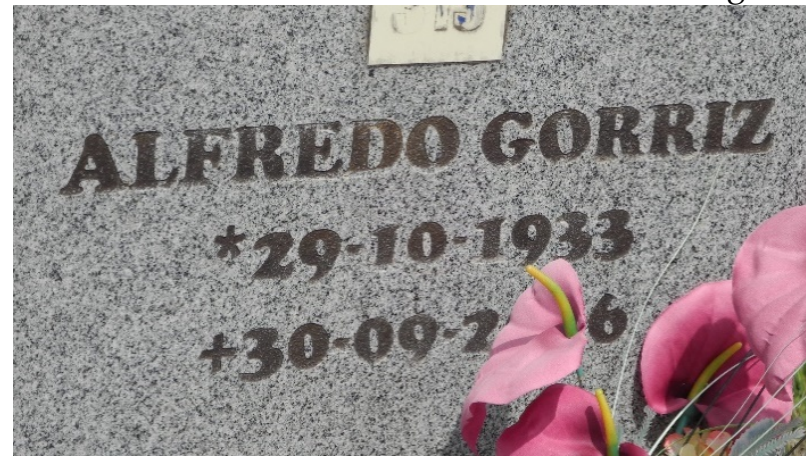

Alfredo Gorriz

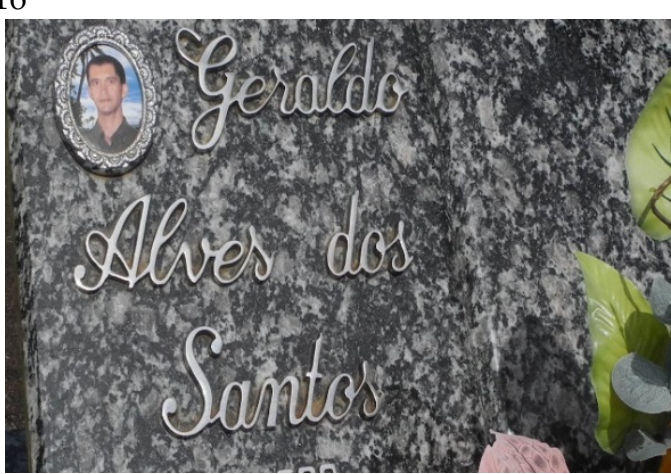

Geraldo Alves dos Santos

Fonte: corpus recolhido pelos autores.

Gorriz. Machado (1984, p.733) registra Gorizo, este já com registros como nome de família desde 1384. O autor acredita que Gorizo está relacionado com o topônimo Goriza. Tibón (2001, p. 109) analisou a forma Gorri, classificada como de origem vasca, de carga semântica "cor vermelha" e base para a alcunha "loiro". Também alcunha na forma derivada Gorría, "o vermelho, o loiro". Conforme Lopez-Mendizabal (1958, p. 495), Gorriz é topônimo na região de Navarra, em Anzuola e em Gipuzkoa Zargal (todas no País Vasco). Tem pouca ocorrência nos dados da CAG, apenas 12 (0.0025\%) no Conselho de Corunha.

Alves. Conforme Machado (1984, p. 116), Alves é variante antroponímica de Álvares. lvares (no esp. Álvarez ou Albares), por sua vez, é patronímico <o filho de Álvaro ${ }^{30>}$ (MACHADO, 1984, p. 114). Alves também é topônimo em terras portuguesas de Almada, Lisboa e Mértola. Esse antropônimo apresenta registro de 1721 ocorrências em território galego (CAG), das quais, 339 (0.0582\%) em Vigo, Província de Pontevedra. A forma também se encontra no patrimônio antroponímico primitivo da Madeira. ${ }^{31}$

\footnotetext{
${ }^{30}$ Na visão de Tibón (2001, p. 115), esse prenome possui origem controversa. Há quem diz que Álvaro venha do alemão alls "todo, muito" e wars "atento", há quem afirme ser de raízes "do gótico warjan, sax. arc. waron, waran $<<$ o que se ofende de todos $>>$ ".

31 "Alluez (Johão) Funchal a.1542" (NUNES; KREMER, 1999, p. 259).
} 
Dos Santos. Nome de família de raízes portuguesas "de origem religiosa, pois foi abrev. de Todos-os-Santos. Dava-se primitivamente às crianças nascidas no dia 1-XI (Nasc. -II, s.v.)" (MACHADO, 1984, p. 1311), o mesmo descreve Guérios (1973, p. 195). Machado (1984, p. 1311) acredita, no entanto, que a popularização desse sobrenome, na maioria dos casos, "se ficou a dever aos que, ao entrarem pelo baptismo na religião cristã, tinham como padrinhos religiosos em cujo nome eclesiástico havia dos Santos." O antropônimo é apresentado nos dados da CAG com 18137 ocorrências totais, com maior registro no Conselho e Província de Corunha - 1822 (0.3754\%).

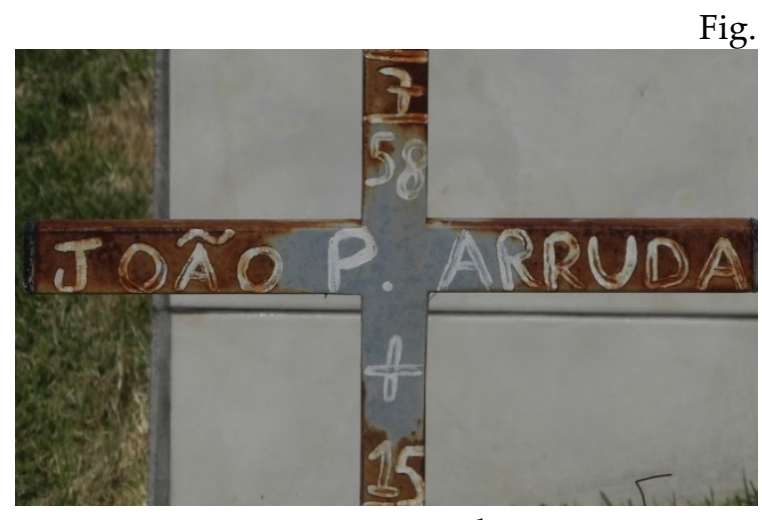

João P. Arruda ${ }^{32}$

Fig. 17 e 18

Fonte: corpus recolhido pelos autores.

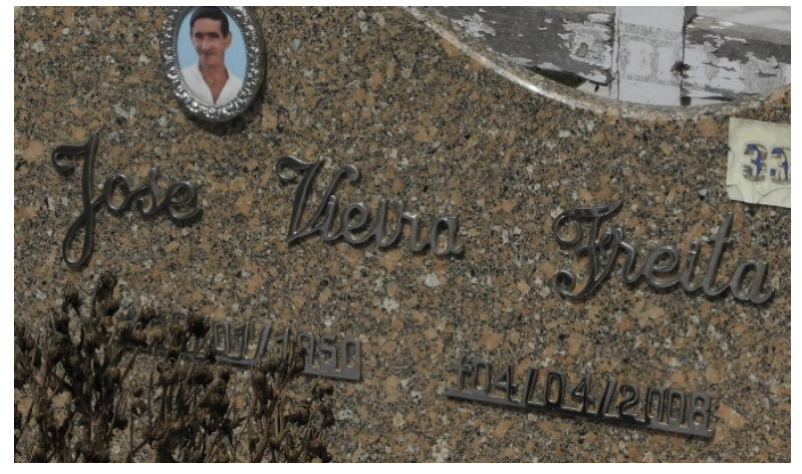

José Vieira Freita

Vieira. Nome de família provavelmente de raízes toponímicas. Machado (1984, p. 1475) relata que Vieira é topônimo frequente na Galiza, na região de Pontevedra, com motivação advinda, em alguns casos, da "concha usada pelos peregrinos a Santiago" (idem, 1984, p. 1475). Como antropônimo, há a forma acompanhada da preposição - de Vieira, mas cedo se atesta a forma sem a preposição de. "Em 1431: <<pero veeira>>" (MACHADO, 1984, p. 1475). Tibón (2001, p. 251) afirma que Vieira (com var. gráfica Vieyra) é variante de Venera, essa última do lat. veneriae "ciertas conchas bivalvas que los peregrinos, al volver de Santiago de Compostela, solían traer cosidas em las

\footnotetext{
32 Esse antropônimo foi descrito na análise da figura 07.
} 
esclavinas; de ellas se originan las insígnias, veneras o vieiras, que los indivíduos de ciertas órdenes llevan colgadas del pecho" (TIBÓN, 2001, p. 251), o mesmo diz Machado (1977, p. 383), "<<espécie de concha>>, assim chamada por semelhança com a concha em que pintam Vénus a sair das águas". Segundo Tavora (1989, p. 351), as raízes toponímicas de Vieira podem derivar "tanto de Vieira do Minho como de Vieira de Leiria". Ainda segundo o autor, "os Vieiras antigos tiraram o apelido da primeira daquelas, e deles se conhece logo em inícios do século XIII a Rui Vieira, sabendo-se que era fidalgo, (...) se sabe que ele honrou a sua terra da comarca de Vieira do Minho" (TAVORA, 1984, p. 351). O nome é registrado na CAG com 997 ocorrências, destas, 221 $(0.0379 \%)$ se localizam em Vigo - Província de Pontevedra. Vieira é numeroso na Antroponímia primitiva da Madeira. ${ }^{33}$

Freita. Segundo Machado (1984, p. 671), provém do lat. fracta, "<<quebrada >> (pedra); $<<$ arroteada $>>$ (terra); <<parcela de uma herdade>>" (idem, p. 671). Conforme o mesmo autor (idem, p. 671), Freita é topônimo português em Arcos de Valdevez, Cabeceiras de Basto, Fafe, Marco de Canaveses, Montalegre, Paredes de Coura, Vieira do Minho. Freita também é topônimo em Lugo, na Galiza. Além de antigo nome de lugar na região de Arouca, "escrito Freitam em doc. de 1132 (...), Fraita em 1143 (...), Frecta em 1220" (idem, p. 671). O registro dessa forma na estatística da CAG apresenta-se com apenas 8 ocorrências no conselho de Negreira, Província de Corunha. No entanto, o registro no plural (Freitas) é mais numeroso, com 803 ocorrências e maior concentração em Vigo - 181 (0.0311\%), Província de Pontevedra. Na Antroponímia primitiva madeirense, Nunes e Kremer (1999, p. 416) registraram apenas a forma Freitas.

\footnotetext{
${ }^{33}$ Nunes e Kremer (1999) documentaram 25 ocorrências na antroponímia primitiva madeirense.
} 


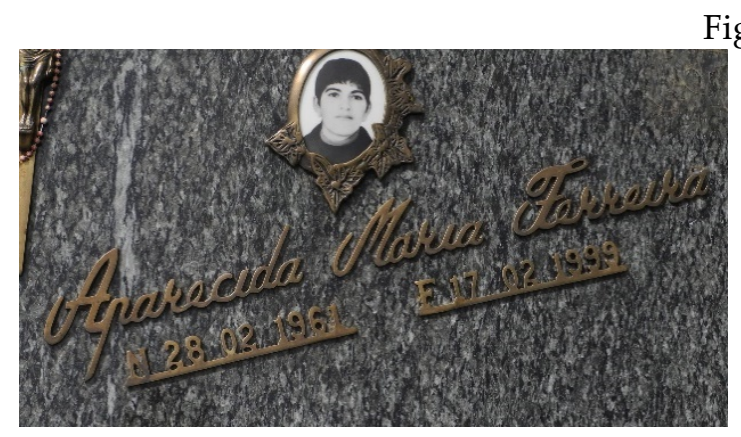

Aparecida Maria Ferreira

Fig. 19 e 20

Fonte: Corpus recolhido pelos autores.

Ferreira. De acordo com Machado (1984, p. 636), do lat. ferrărīa, "mina de ferro". É nome de família muito frequente tanto em Portugal quanto no Brasil. Em muitos casos esse antropônimo tem motivação toponímica, uma vez que é um nome de lugar muito corriqueiro em Portugal, na Galiza e no Brasil. Eis o caso das localidades "Ferreira no Alentejo, vila no distrito de Beja, Ferreira do Zêzere, idem no de Santarém, etc. Ferreiras, Albufeira, Covilhã, Évora, Mora (Quintas das Ferreiras), Oliveira do Hospital (Lameiro das Ferreiras), Penafiel; na Galiza: Corunha, Lugo, Orense" (MACHADO, 1984, p. 636). Ferreira também nomeia um dos afluentes do rio Sousa, o qual deságua no Douro (norte de Portugal). Conforme o mesmo autor (idem, p. 671), esse cognome já aparece nomeando pessoas em registros do séc. XIII "esto per dito, chegou Pero Ferreira", assim como um tal de Salvador Feerero referenciado em um diploma latino de 1352 pelo rei Eduardo III da Inglaterra. Conforme Tavora (1989, p.170), o antropônimo Ferreira tem raízes toponímicas, "segundo alguns autores, na designação da vila de Ferrera ${ }^{34}$, em Castela, hoje Herrera de Rupisverga, havendo outros que a dão numa das várias vilas portuguesas com o mesmo nome" (idem, p. 170). De Ferreira também se conhecem as variantes antroponímicas Ferreiria e Ferreirinha (idem, p. 636). Este nome nos dados da CAG tem ocorrência de 7694 registros, com maior destaque no conselho de Vigo 1275

\footnotetext{
${ }^{34}$ Itálico nosso.
} 
$(0.2189 \%)$, Província de Pontevedra. Ferreira é forma muito frutífera na Antroponímia primitiva da Madeira (NUNES; KREMER, 1999).

Gomes. Conforme a análise de Machado (1984, p. 726), Gomes é patronímico advindo de Goma ou Guma, Gomici. Guma tem raiz no gótico e significa "homem" (PIEL apud MACHADO, 1984, p. 726), o mesmo diz Tibón (2001, p.114). No castelhano, há a variante Goméz, qual Tibón (2001, p. 114) vê como forma patronímica de Gome, nome de pessoa desde 812. A CAG apresenta 485 registros, dos quais 84 em Vigo $(0.0144 \%)$, na Província de Pontevedra. Gomes e Gomez são formas muito ocorrentes na Antroponímia da Madeira (NUNES; KREMER, 1999).

De Oliveira. Leite de Vasconcelos (1931, p. 384) afirma que Oliveira descende do lat. olveira (= ulveira). Como a própria preposição <de $>$ indica, essa forma tem raízes toponímicas, assim também afirma Leite de Vasconcelos (1928, p. 166). Como topônimo, é muito frequente em Portugal ${ }^{35}$, na Galiza - Corunha, Orense e Pontevedra - e no Brasil - Minas Gerais e Bahia (MACHADO, 1984, p. 1092). Na toponímia galega, Oliveira e Oliveiroa, e na castelhana, Olvera e Olveda (idem, p.1092). Tavora (2001, p. 272) acredita que esse nome de família "foi tirado da designação do Paco de Oliveira, na freguesia de Santa Maria de Oliveira, termo de Arcos de Valdevez" (idem, p. 272). A CAG apresenta 3710 ocorrências para este nome, dos quais 743 estão em Vigo (0.1276\%). Na Antroponímia primitiva da Madeira, o antropônimo se apresenta nas formas Oliueyra (1483), Olyueira (1509), Oljueira (1509), Holliueyra (1494), entre outras (NUNES; KREMER, 1999).

\footnotetext{
35 "A variante Ulveira encontra-se noutros topónimos medievais, como Santa Eulália de Ulveira (hoje Oliveira do Douro)". Disponível em: https://www.infopedia.pt/dicionarios/toponimia/Oliveira. Acesso em: 23 fev. 2020.
} 
Fig. 21

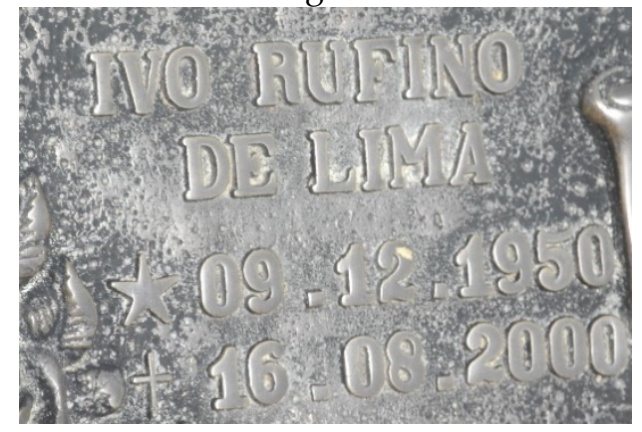

Ivo Rufino de Lima

Fonte: corpus recolhido pelos autores.

Rufino. Leite de Vasconcelos (1928, p. 70), Machado (1984, p. 1283), Guérios (1973, p. 191) e Tibón (2001, p. 213) apresentam Rufino como derivado do latim Rufinu, um antropônimo relacionado a $r u f u s^{36}$, que na etimologia significa ruivo, avermelhado (GUÉRIOS, 1973, p. 191). Machado (idem, p. 1283) destaca que houve vários santos com esse nome, "o pai de S. Silvestre chamava-se assim" (idem p. 1283), e na toponímia destaca-se a cidade de Alter do Chão em Portugal (idem, p. 1284). Nos números da CAG o nome apresenta pouco uso, apenas no Conselho e Província de Corunha, 6 registros (0,0012\%). O sobrenome também se encontra documentado na Antroponímia italiana. ${ }^{37}$

De Lima. A forma Lima possui duas origens etimológicas: a lima (ferramenta) tem origem do lat. lìma, com mesmo sentido, já a lima (fruta) advém do ár. Lìm, "divergente de līmūn, mesmo sentido" (MACHADO, 1977, p. 420). De raízes toponímicas, segundo Machado (1984, p. 880), o nome inicialmente tinha relação com os originários da região do rio Lima, na Província do Minho, no noroeste da Hispânia. Segundo o autor, Lima também nomeou diversas cidades ao entorno do rio de mesmo nome. Também ressalta

\footnotetext{
${ }^{36}$ Para Machado (1977, p.125), do lat. rūfu- (avermelhado, ruivo, ruço).

37 "Corrisponde a una variante con -f- scempia del personale Ruffino (v. Ruffìn). Amicus Rufinus è documentato ad Alessandria nel 1192 (...). Il nome di famiglia Rufino risulta a Napoli, altrove in Campania e a Potenza e provincia" (CAFFARELLI; MARCATO, 2008, p. 1486).
} 
que a forma Lima está para Limia (forma castelhana e galega de Lima) e que há referências toponímicas com essa forma na Província de Orense: Ginzo de Limia, Portela de Limia, Sabucedo de Limia e outros (MACHADO, 1984, p. 881). Em terras portuguesas, Leite de Vasconcelos (1928, p. 158) cita a forma, como nome relacionado a rios, tais como as localidades de Ponte de Lima e Viana do Lima, para o autor, "é natural que umas vezes os apelidos sejam abreviaturas de nomes de terras, outras vezes tomados directamente dos rios, como epônimos de regiões que eles banham" (LEITE DE VASCONCELOS, 1928, p. 158).

Guérios (1973, p. 145) menciona o nome Límia como pré-românico e o relaciona com a lenda do rio Lethes, o rio do esquecimento, "quem atravessasse esse rio ficaria esquecido de tudo". Ao que tudo indica, tratava-se do rio Lima, que nasce na Galiza e, desse fato, se remete à história da invasão romana na Península Ibérica.

Segundo Tavora (1989, p. 223), a linhagem do nome Lima, na Galiza, se daria a partir de D. Juan Fernandez de Lima (o Bom) e, em Portugal, a partir do século XIII passou para Juan Fernandez de Lima (o Batissela) a que seguiu outras gerações que tiveram o senhorio de Ponte de Lima.

Na toponímia, Machado (1984, p. 881) aponta que Lima é muito frequente em Portugal e nomeia nomes de pátios, quintas, moinhos etc. E, no Brasil, cita a cidade de Nova Lima em Minas Gerais e que, inicialmente, era chamada de Vila Nova de Lima (1891). O antropônimo na CAG é apresentado com 979 ocorrências totais, sendo a maior concentração na Província de Pontevedra, Conselho de Vigo - 268 (0.046\%). Na Antroponímia primitiva da Madeira, Nunes e Kremer (1999) encontraram 4 registros de Lima (Lyma). 
Como nome de família, Lima também se encontra na língua italiana. Caffarelli e Marcato (2008, p. 982) registram que Lima é sobrenome italiano com raízes na cidade de Palermo e conta com em torno de 1500 portadores $^{38}$.

\section{Considerações finais}

Como observado nas descrições etimológicas, a maioria dos nomes de famílias coletados possui alguma relação com a história e a natureza física ou humana da Península Ibérica. Pode-se ver as marcas da saudade da terra sagrada dos árabes que se assentaram na Península no caso da forma Medina; a religiosidade dos portugueses nos antropônimos Todos os santos e Ramos; os rios e os lugarejos do interior ibérico (nos casos de Lima; Ferreira, Freita, Vieira, Vilas Boas, do Prado, Camargo etc.); pré-nomes já arcaicos na língua (na forma Gomes); a natureza autóctone ibérica (nas formas Arruda, Pereira, Oliveira e Moreira); e o substrato linguístico deixado no contexto autóctone ibérico (nas formas Gorriz e Gôngora).

Dessa forma, concluímos que o desafio da Onomástica não é apenas revelar o passado que os nomes escondem senão de também mostrar a história migratória que cada forma antroponímica desenha. Em particular, as transformações na grafia, como o processo de lusitanização ${ }^{39}$. Por sua vez, o cemitério do município de Iguatu - PR é apenas uma amostra da diversidade de nomes e alterações pelas quais passaram o elemento antroponímico dessa região.

\footnotetext{
38 "Incerta una derivazione da un soprannome da lima utensile, o da un nome femminile Lima che è attestato in epigrafi latine, piuttosto che da una voce lima 'limone dolce (...); il cognome è di Palermo e della provincia (Trabia, Bagheria), e inoltre a Caltanisseta, nell'Ennese e altrove in Sicilia, con gruppi in Campania, a Roma e a Torino risultato di movimenti migratori" (CAFFARELLI e MARCATO, 2008, p.982).

${ }^{39}$ Eis o caso da forma Gôngora.
} 


\section{Referências bibliográficas}

ARRUDA, J. J. de A.; FERLINI, V. L. A.; MATOS, M. I. S. de; SOUSA, F. de (org.). De colonos a imigrantes: I(e)migração portuguesa para o Brasil. São Paulo: Alameda, 2013.

BLANCO, J. A. Emigración y asociacionismo español en Brasil. In: SOUSA, F. de; MATOS; I. de L.; MATOS, I. Nas duas margens. Os portugueses no Brasil. Porto: Afrontamento, 2009. p. 189-212.

BAYLON, C.; FABRE, P. Les noms de lieux et de personnes. Paris: Editions Fernand Natans, 1982.

BOUDIN, M. H. Dicionário de Tupi moderno: dialeto tembé-ténêtéhar do alto do rio Gurupi. Vol. I. São Paulo: Conselho Estadual de Artes e Ciências Humanas, 1978.

BOULLÓN AGRELO, A. I.; SOUZA FERNÁNDEZ, X. (dir.). Cartografía dos apelidos de Galicia. Santiago de Compostela: Instituto da Lingua Galega. Disponível em: http://ilg.usc.es/cag. Acesso em: 22 nov. 2019.

CAFFARELLI, E.; MARCATO, C. I Cognomi D'Italia: Dizionario Storico ed Etimologico. Vol. 1 H-Z, Torino: Garzanti, 2008.

CANÓVAS, M. D. K. A emigração espanhola e a trajetória do imigrante na cafeicultura paulista: o caso de Villa Novaes, 1880-1930. Dissertação de Mestrado USP, São Paulo, 2001.

CARDOSO, J. A.; WESTPHALEN, C. M. Atlas Histórico do Paraná. 2.ed. ver. ampl. Curitiba: Livraria do Chain, Editora, 1986.

DAUZAT, A. Dictionnaire Étymologique des Noms de Famille et Prénoms de France. Paris: Librairie Larousse, 1951.

Diccionario de la Lengua Española (DEL) - Real Academia Española (RAE). Gamón. Disponível em: http://dle.rae.es/?id=IpVeY4k. Acesso em: 25 mar. 2020.

Dicionário infopédia de Toponímia. Oliveira. Porto: Porto Editora, 2003-2020. Disponível em: https://www.infopedia.pt/dicionarios/toponimia/Oliveira. Acesso em: 23 fev. 2020 
GOOSSENS, J. Familiennamengeographie. In: HSK 11.2 Namenforschung. Teilb. 2, Berlin und New York: Walter de Gruyter, 1996.

GORTER, D. Introduction: The Study of the Linguistic Landscape as a New Approach to Multilingualism. In: GORTER, D. (ed.). Linguistic Landscape: A New Approach to Multilingualism. Clevedon: Multiligual Matters, 2006. p. 01-06. DOI https://doi.org/10.21832/9781853599170

GUÉRIOS, R. F. M. Dicionário Etimológico de Nomes e Sobrenomes. 2 ${ }^{\underline{a}}$ Ed. São Paulo: Editora Ave Maria Ltda, 1973.

LEITE DE VASCONCELOS, J. Antroponímia portuguesa. Lisboa: Imprensa Nacional, 1928.

LEITE DE VASCONCELOS, J. Opusculos III: onomatologia. Coimbra: Imprensa da Universidade, 1931.

LOPEZ-MENDIZABAL, I. Etimologias de apellidos vascos. Buenos Aires: Ediciones Libreria del Colegio, 1958.

MACHADO, J. P. Dicionário Onomástico Etimológico da Língua Portuguesa. 3 v., Lisboa: Editorial Confluência, 1984.

MACHADO, J. P. Dicionário Etimológico da Língua Portuguesa. Lisboa: $3^{a}$ ed. 5 v., Livros Horizonte, 1977.

MATOS, M. I. S. de; SOUSA, F. de; HECKER, A. Deslocamentos e história: os portugueses. Bauru - SP: Edusc, 2008.

NUNES, N. N; KREMER, D. Antroponímia primitiva da Madeira e Repertório onomástico histórico da Madeira (séculos XV e XVI). Tübingen: Max Niemeyer Verlag, 1999. DOI https://doi.org/10.1515/9783110909425

Portal IBGE Cidades@. Iguatu. In: Instituto Brasileiro de Geografia e Estatística. Disponível em: https://cidades.ibge.gov.br/brasil/pr/iguatu/panorama. Acesso em: 25 mar. 2020.

TAVORA, L. de L. e. Dicionário das famílias portuguesas. Lisboa: Quetzal Editores, 1989. 
TIBIRIÇÁ, L. C. Dicionário de Topônimos brasileiros de origem tupi: significação dos nomes geográficos de origem tupi. Santos: Traço Editora. 1. Ed., 1985.

TIBÓN, G. Diccionario etimológico comparado de nombres propios de persona. México: Fondo de Cultura Económica, 1986.

TIBÓN, G. Diccionario etimológico comparado de los apellidos españoles, hispanoamericanos y filipinos. 3ª ed. México: FCE, 2001. 